\title{
ASSESSMENT AND OPTIMISATION OF LUNG CANCER PATIENTS FOR TREATMENT WITH CURATIVE
}

\section{INTENT}

Dr Clare Harris* $\mathrm{MRCP}^{1}$, Dr David Meek* MRCP ${ }^{1}$, Dr David Gilligan FRCPE FRCR ${ }^{1}$, Dr Lynne Williams PhD MRCP2 ${ }^{2}$ Mr Piergiorgio Solli MD PHD ${ }^{3}$, Dr Robert C Rintoul PhD FRCP ${ }^{1}$

*Authors contributing equally

1. Department of Thoracic Oncology, Papworth Hospital, Papworth Everard, Cambridge CB23 $3 R E$

2. Department of Cardiology, Papworth Hospital, Papworth Everard, Cambridge CB23 3RE

3. Department of Cardiothoracic Surgery, Papworth Hospital, Papworth Everard, Cambridge CB23 3RE

Authors declare no conflicts of interest

Corresponding author:

Dr Robert C Rintoul

Department of Thoracic Oncology

Papworth Hospital

Cambridge

CB23 3RE

\section{Key words}

Lung cancer; staging; fitness; lung function; radiotherapy; surgery; chemotherapy; optimisation 


\section{Acknowledgements}

Robert Rintoul is part funded by the Cambridge Biomedical Research Centre and the Cambridge Cancer Centre. 


\section{Abstract}

Over the past decade the field of lung cancer management has seen many developments. Coupled with an ageing population and increasing rates of co-morbid illness, the work-up for treatments with curative intent has become more complex and detailed.

As well as improvements in imaging and staging techniques, developments in both surgery and radiotherapy may now allow patients who would previously have been considered unfit or not appropriate for treatment with curative intent to undergo radical therapies.

This review article will highlight literature relating to investigation and staging techniques, together with assessments of fitness, with the aim of helping clinicians determine which are the most appropriate treatments for each patient. We also highlight areas where further research may be required. 


\section{$\underline{\text { Introduction }}$}

It is well established that surgical resection offers patients the best chance of long term cure in early stage lung cancer ${ }^{1}$. Over the past decade there has been a successful drive to increase the number of patients undergoing resection, with the greatest increase in resection rates being noted in older age groups $^{2,3,4,5}$. The advent of Video Assisted Thoracoscopic Surgery (VATS) is further improving access for some who previously would not have been deemed suitable for surgical resection ${ }^{6,7}$. In addition to surgery, increasing numbers of patients who may not be eligible for surgical resection on grounds of fitness or disease extent are being offered radical radiotherapy or chemoradiotherapy with potential curative intent. Although further work is required, Stereotactic Ablative Radiotherapy (SABR) may offer similar benefits to surgical resection in very early stage disease where the disease is localised to a small primary lesion ${ }^{8,9}$.

As our population ages, the median age of those presenting with lung cancer is increasing and many coming forward for treatment have significant co-morbidities. It is therefore imperative that we develop systems to ensure accurate assessments of physical health including cardiopulmonary reserve, alongside clear diagnostic and staging algorithms which allow as many patients as possible to be treated with curative intent ${ }^{4}$.

In this review we outline the current evidence and guidelines available to assist with assessment and optimisation of lung cancer patients for treatment with curative intent.

Although assessments for fitness and staging should be undertaken in parallel, for clarity we will address these issues separately. A holistic approach should be undertaken with an early assessment of fitness and performance status as this will begin to inform which treatment modalities may be possible for a given individual and depending upon disease extent, this will influence the most appropriate investigations (Figure 1).

\section{Diagnostic and Staging Investigations - imaging}

Accurate staging is essential for identifying the best treatment for each patient, leading to optimal treatment outcomes. Over the last 15 years there has been a significant change in the approach to lung cancer staging with improvements in cross-sectional and functional imaging and a move away 
from surgical staging techniques towards minimally invasive approaches such as endobronchial and endoscopic ultrasound.

\section{Chest radiograph}

Although most patients who present to a lung cancer service will have had a chest radiograph, the sensitivity and specificity of chest radiography for detecting lung cancer is low. Approximately one quarter of patients with lung cancer have a "normal" chest radiograph at presentation ${ }^{10,11}$. In the presence of 'red flag symptoms' such as chronic cough, weight loss or haemoptysis, computed tomography is advised ${ }^{12}$.

\section{Computed tomography (CT)}

Modern multi-detector computed tomography allows images of the entire chest to be acquired in a single breath hold. The standard staging scan should be an intravenous contrast enhanced, volumetric thin slice $(\leq 1 \mathrm{~mm}) \mathrm{CT}$ which includes the chest and abdomen at least. Some units also advocate the extension of this imaging field to include the pelvis to aid assessment for bone metastases. Post processing techniques allow multi-planar reconstructions in coronal and sagittal planes, which are often useful for planning surgical or radiotherapy treatments.

\section{Positron emission tomography/computed tomography (PET-CT)}

PET-CT has been shown to be superior to standard CT in the diagnosis and staging of lung cancer ${ }^{13-16}$. PET-CT is currently recommended by NICE as the preferred imaging modality for identifying both intra-thoracic and distant metastatic disease in lung cancer patients being considered for treatment with curative intent ${ }^{17}$. Reported sensitivity and specificity of PET-CT for detecting metastases in intrathoracic lymph nodes ranges from $85-89 \%$ and $84-94 \%$ respectively, compared with $70 \%$ and $69 \%$ respectively for $\mathrm{CT}$ alone ${ }^{18}$. In patients being considered for treatment with curative intent histological confirmation is often required to confirm the PET CT findings as false positive results may occur with inflammatory/infective conditions. Occult N2 disease has been described in up to $16 \%$ of PET-CT negative nodes at the time of surgery with higher prevalence seen in patients with PET-CT positive N1 nodes measuring $>16 \mathrm{~mm}$, central/RUL tumours, primary tumours with SUV $>10$ and adenocarcinoma cell type ${ }^{19}$.

Detection of unsuspected lymph node metastases (upstaging) depends on removal or sampling of lymph nodes, which is likely dependent on the completeness of the lymph node dissection and this strictly correlates with the surgical technique. Previous reports investigated the efficacy of lymph 
node dissection during VATS and open lobectomy and found these were comparable ${ }^{20,21}$, but recent data from The Society for Thoracic Surgeons (STS) database showed that nodal upstaging was significantly lower after lobectomy by VATS than after thoracotomy ${ }^{22}$.

Current NICE guidelines recommend that mediastinal nodal sampling should be performed for all PET positive or PET negative nodes that measure $>1 \mathrm{~cm}$ in short axis. Normal sized mediastinal nodes that show no tracer uptake on PET-CT do not require further sampling ${ }^{17}$.

\section{Diagnostic and staging investigations - pathological confirmation}

Accurate pathological diagnosis is key to determining the optimal treatment for patients with lung cancer. Current national clinical guidelines state that lung cancer should be histologically confirmed whenever practical and make clear recommendations around the sequence of investigations that should be used to diagnose and stage lung cancer ${ }^{17}$. Patients being considered for treatment with curative intent should have CT and PET-CT performed prior to biopsies being undertaken. If, following these investigations, treatment with curative intent is still considered possible the biopsy approach chosen should be designed to provide as much diagnostic and staging information as possible. For instance, a small peripheral lesion staged T1aNOMO by CT and PET-CT may require a CT guided needle biopsy only. On the other hand a larger peri-hilar lesion staged T2bN2M0 by PET-CT may require mediastinal staging to clarify whether mediastinal nodes are involved, followed by a biopsy of the primary lesion if the mediastinal biopsy is negative for malignancy.

\section{Assessment of the mediastinum}

Accurate assessment of hilar mediastinal nodal involvement is becoming increasingly important in order to determine optimal treatment for patients being considered for treatment with curative intent. Although surgical staging (predominantly cervical mediastinoscopy) has historically been considered the 'gold standard,' a number of trials have provided high-level evidence for the efficacy of Endobronchial Ultrasound (EBUS) leading to inclusion in national lung cancer staging guidelines. When combined with endoscopic ultrasound (EUS) the majority of the mediastinum can be assessed and combined EBUS/EUS has been shown to have equivalent accuracy to surgical staging ${ }^{23}$ and has been shown to be cost-effective ${ }^{24}$. Although EBUS/EUS has reduced the need for surgical staging in lung cancer, cervical mediastinoscopy should still be considered following a 'negative for malignancy' result if a high degree of clinical suspicion of mediastinal nodal involvement remains ${ }^{25,26,27}$ and the 
result will have a significant impact on management. Although mediastinal staging has traditionally been considered in the context of staging prior to lung resection, it is increasingly realised that accurate hilar and mediastinal staging is important for patients being assessed for oncological treatments. For instance EBUS/EUS can assist in mediastinal evaluation of radiotherapy field planning and with the increasing use of SABR, we are finding that EBUS is useful for assessing ipsilateral hilar and mediastinal nodes that are concerning on CT or PET-CT ${ }^{28}$.

\section{Assessment of fitness for surgical treatment}

Age

Although age can be associated with an increased number of significant comorbidities, age alone should not exclude a patient from being considered for surgical treatment ${ }^{29,30,31}$.Approximately 30 $35 \%$ of candidates for surgical resection of lung cancer are aged $>70$ years $^{32}$. Several guidelines focussing on decision-making in elderly patients with lung cancer agree that assessments of cardiovascular and pulmonary fitness for surgery should be performed independent of age ${ }^{17,31,32,34}$.

\section{Performance Status (PS)}

The Eastern Cooperative Oncology Group (ECOG) performance status and the Karnofsky performance status (KPS) are the most widely used tools to assess the functional status of cancer patients. Both tools describe the symptoms and functional abilities of patients with respect to their ambulatory status, and the ECOG and KPS scales have been shown to correlate well with one another both prior to and after treatment for lung cancer ${ }^{35}$. The ECOG score has been shown to have a slightly better prognostic predictive ability and is now more widely used in lung cancer assessment (table 1$)^{35,37}$. Some studies have shown significant interpreter variability and when there is uncertainty around the PS of a patient that may alter treatment options, it is advisable to assess fitness further ${ }^{36}$.

\section{Cardiovascular evaluation prior to lung resection}

Many patients presenting with disease which is amenable to treatment with curative intent have underlying cardiopulmonary diseases secondary to cigarette smoking. In these patients the 
perioperative risks of surgery and potential for long-term subsequent disability must be balanced against the potential benefit of curative treatment.

There are currently three main sets of guidelines for the assessment of fitness of patients being considered for treatment of lung cancer with curative intent ${ }^{32,33,38}$. The British Thoracic Society (BTS) incorporates the guidelines from the American College of Cardiology (ACC) and the American Heart Association (AHA) and suggests a focus on three major areas; the risk of post-operative cardiac event, dyspnoea and the perioperative risk of mortality (see Figure 2$)^{39}$.

Myocardial infarction (MI) is a major cause of mortality in patients undergoing non-cardiac surgery. The prevalence of underlying coronary artery disease (CAD) in patients with lung cancer is between $11 \%$ and $17 \%$, and the risk of myocardial infarction or death in all patients undergoing lung resection surgery is estimated to be $1-5 \%{ }^{39}, 40$. Limitations in exercise tolerance secondary to CAD can be masked by lung disease and it is therefore recommended that careful assessment is made ${ }^{39}$. In patients who are known to have had a recent myocardial infarction, NICE recommend that surgery should be avoided for at least 30 days $^{17}$.

Preoperative evaluation of cardiovascular disease should include focused history-taking, examination, and 12-lead electrocardiography (ECG), as well as calculation of the Thoracic Revised Cardiac Risk Index (ThRCRI) ${ }^{36}$. The ThRCRI was developed in recognition that the original Revised Cardiac Risk Index (RCRI) was inaccurate at predicting cardiovascular complications in patients undergoing lung resection ${ }^{40,42}$. The ThRCRI risk score incorporates multiple patient factors (see table 2 ) and the extent of planned lung resection in order to stratify patients into risk categories for developing cardiovascular complications (table 3). It has been validated both in single centre studies and in a multicentre review $\mathrm{w}^{43,44,45}$ and current guidelines recommend it for stratification of risk of

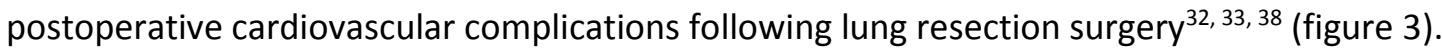

Pre-operative non-invasive testing is aimed primarily at the detection of left ventricular dysfunction, myocardial ischaemia, and significant valvular heart disease. While routine pre-operative echocardiography is not necessary in all patients, it is reasonable in patients undergoing major intrathoracic surgery (e.g. pneumonectomy), and in patients with a history of pre-existing cardiovascular disease ${ }^{46}$. If cardiac conditions are discovered or suspected, or patients have an ThRCRI score $>2$, then patients should be assessed by a cardiologist; in these cases functional imaging for evidence of reversible ischaemia is warranted as patients may require preoperative optimisation (2014 ESC guidelines) 38,46 
Patients with identified CAD should have their anti-anginal medications optimised; current evidence is in favour of continuing beta blockade in established patients, along with antiplatelet therapy and statins. However, it is not recommended to routinely initiate beta blockade in patients who are treatment naïve immediately prior to surgery as this may increase the risk of cerebrovascular accident despite offering some protection against non-fatal $\mathrm{MI} \mathrm{I}^{45}, 47$. Patients who may benefit from the introduction of beta-blockers preoperatively are those with a high number of cardiac risk factors, and those with known ischaemic heart disease or myocardial ischaemia ${ }^{48}$.

No significant increase in peri-operative major cardiac events has been demonstrated in patients with inducible ischaemic affecting less than $20 \%$ of the total left ventricular myocardium ${ }^{49}$. However, in the presence of a significant ischaemia burden, particularly if symptoms of angina exhibit an unstable or crescendo pattern, revascularization prior to surgery should be considered as it may reduce the risk of postoperative $\mathrm{MI}$ and death ${ }^{38,50}$. Cardiac revascularisation of CAD with myocardial ischaemia is therefore recommended in cases where the surgical resection can be delayed safely for this to take place ${ }^{46,48}$.

\section{Thoracoscore}

The National Lung Cancer Audit 2011 reported the 30-day mortalities for lobectomy and pneumonectomy procedures to be $2.3 \%$ and $7.0 \%$ respectively $38,51,52$. Given the number of variables that impact on an individual's risk of dying in the postoperative period, holistic scoring systems are required in helping predict which patients are at greatest risk.

The BTS and NICE guidelines recommend the Thoracoscore for predicting perioperative hospital mortality ${ }^{17,38}$. Thoracoscore incorporates the effect of nine variables to give a pre-operative prediction of patient mortality; age, gender, ASA classification, WHO performance status, Medical Research Council dyspnoea score, priority of surgery, procedure class, diagnosis and comorbidity score $^{53,54}$.

For patients undergoing pneumonectomy, some recent studies have indicated that it may overestimate mortality in high risk groups, whilst underestimating risk in low risk groups ${ }^{55}$. When applied to a large UK-based population it appeared to generally overestimate mortality ${ }^{56,57}$. Therefore, although Thoracoscore remains the most holistic and validated scoring system, it should be interpreted with caution when deciding whether or not to offer surgical treatment for lung cancer. 
Spirometry, diffusion capacity and predicted postoperative (PPO) lung function

Basic spirometry and diffusion capacity are commonly used to initiate assessment of respiratory function prior to surgery. Spirometry alone is a less sensitive predictor of postoperative mortality than diffusion capacity and for this reason should not be used in isolation for assessment ${ }^{38,58,59}$.

Predicted postoperative (PPO) FEV1 or PPO TLCO for patients who are being considered for lobectomy is usually calculated by dividing the preoperative lung function by the total number of preoperative bronchopulmonary segments (usually nineteen), and then multiplying it by the number of segments that will remain postoperatively ${ }^{17,60}$. This is a crude measurement as these calculations cannot take into account the functionality of each segment.

The 2010 BTS guidelines suggest that there is a poor clinical correlation between PPO lung function (PPO FEV1 and PPO TLCO) and the postoperative quality of life score ${ }^{38,61,62}$. One study found that when a lower PPO FEV1 threshold of $30 \%$ was applied (rather than previous minimum of $40 \%$ ), patients continued to have acceptable postoperative mortality rates $(4 \%)$ and better than predicted postoperative lung function ${ }^{63}$.

The use of PPO FEV1 is further limited because some patients can benefit from a lung volume reduction surgery effect ${ }^{32,64,65}$. In patients with emphysema, reduction in the volume of emphysematous parenchyma can improve lung function, and therefore in patients with lung cancer and concomitant emphysema the postoperative FEV1 can be underestimated ${ }^{66}$. Conversely, PPO FEV1 can substantially overestimate the actual FEV1 observed in the early postoperative phase when most complications occur 67,68 .

Patients and physicians may be concerned about the prospect of potentially life-altering dyspnoea after lung resection. The BTS now recommends that rather than using a firm cut-off for the lower limit of PPO FEV1, a discussion with the patient about potential risks is considered ${ }^{38}$. This approach is supported by the current NICE guideline, which advises that patients with a PPO FEV1 or PPO TLCO below the recommended lower limit of $30 \%$ still be considered for surgical treatment if they accept the risk of postoperative breathlessness and complications ${ }^{17}$.

Exercise testing; 6-minute walk, shuttle tests and cardiopulmonary exercise testing 
The shuttle and the 6-minute walk tests deliver an objective measure of exercise capacity. The 6 minute walk test asks a patient to walk as far as possible within 6 minutes and enables them to rest as needed. Results correlate well with VO2 max (maximal oxygen consumption measured by cardiopulmonary exercise testing), but it is debatable whether it enables prediction of postoperative outcomes ${ }^{33,69,70 .}$

The shuttle test requires the patient to walk back and forth between fixed points at increasing speed until they are unable to maintain the required speed. This method has been shown to correlate well with the VO2 $\max \left(25\right.$ shuttles correlating to a VO2 $\max$ of $10 \mathrm{~mL} / \mathrm{kg}^{-1} / \mathrm{min}^{-1}$ ) but may not differentiate patients who later develop postoperative complications ${ }^{71,72}$. The current BTS guidelines advocate the use of the shuttle test in patients with borderline lung function testing; where the patient manages $>400 \mathrm{~m}$ during the test this can be used as a marker of good preoperative function and only patients who fail this test or have other risk factors will require formal cardiopulmonary exercise testing (CPET) $)^{33,38}$.

CPET is a non-invasive test of exercise capacity, and is recommended for assessment of patients with PPO FEV1 or PPO TLCO $<30 \%$ predicted $^{32}$, and for patients with a moderate-high risk of postoperative breathlessness ${ }^{38}$. Patients exercise on a treadmill or an exercise bike, with continuous monitoring of multiple parameters including VO2 max. As well as being a highly reproducible method of quantifying exercise capacity, CPET can often enable clinicians to establish the underlying cause of the limitations and to treat or optimise them where possible. Current guidelines recommend using VO2 $\max >15 \mathrm{~mL} / \mathrm{kg} / \mathrm{min}$ as a marker of good function ${ }^{38}$, and suggest that a VO2 max of $>20 \mathrm{ml} / \mathrm{kg} / \mathrm{min}$ (or $>75 \%$ predicted) can be used as a cut off as a safe measure for patients who are being considered for pneumonectomy. Conversely a VO2 $\mathrm{max}<10 \mathrm{ml} / \mathrm{kg} / \mathrm{min}$ (or $<35 \%$ predicted) indicates high risk for any lung resection (see figure 4$)^{33 .}$

\section{Ventilation/perfusion scans}

Quantitative ventilation-perfusion scanning enables an assessment of the percentage function of each lung and individual zones, and is one of the most commonly used methods of assessing patients prior to pneumonectomy. Scintigraphy is less commonly adopted in patients undergoing lobectomy because it offers a picture of the regional distribution (upper/mid/lower zones) rather than the actual contribution of each individual lobe or segment.

Ventilation-perfusion scintigraphy enables a calculation of the PPO FEV1 or TLCO based on the functional activity of the remaining lung parenchyma and the preoperative FEV1 or TLCO. Both 
ventilation and perfusion scintigraphy have been shown to provide high quality predictions of PPO lung function although there seems to be no additional benefit in performing both ${ }^{73,74,75}$. The ERS/ESTS clinical guidelines on fitness for radical therapy in lung cancer patients (2011) advise that patients with borderline lung function testing have ventilation/perfusion scintigraphy prior to pneumonectomy ${ }^{33}$.

\section{Assessment for curative, non-surgical treatments}

Although surgery remains the gold standard treatment for patients with early stage lung cancer, those with good PS (performance status), deemed to have non-operable disease or who decline surgery should still be considered for curative treatments with radiotherapy or chemoradiotherapy. Generally patients with localised disease who are PS 0-1, without significant co-morbidities are suitable. Some PS 2 patients may also be suitable but careful selection and counselling are required. In very early stage, localised disease, some PS 3 patients can be considered for SABR therapy dependent on the cause of their limited function.

Patients with stage I-III NSCLC not suitable for surgery should be assessed by a Clinical Oncologist specialising in thoracic oncology ${ }^{17}$. Patients with limited stage SCLC and good performance status should also be considered for combination chemoradiotherapy ${ }^{17}$. Non-surgical patients with stage III NSCLC should be offered curative radiotherapy with various fractionation regimes including stereotactic ablative radiotherapy (SABR), continuous hyperfractionated accelerated radiotherapy (CHART) or conventionally fractioned radical radiotherapy undertaken over a 4 - 6.5 week period. In addition patients with stage II-III disease should also be considered for chemoradiotherapy providing survival benefit is balanced with the risk of toxicity.

\section{Radiotherapy with curative intent}

Patients are required to lie in a semi-recumbent position and maintain this for the duration of their radiotherapy treatments. Each can take greater than 30 minutes to complete and patients may require supports, analgesics or oxygen in order to help maintain comfort and position.

Effective radiotherapy must target tumours whist protecting surrounding organs at risk (OARs). There are no current guidelines demonstrating a "safe" lower limit of lung function for radiotherapy 
and those with poor lung function should still be considered for radiotherapy provided the tumour volume is small ${ }^{17,33}$. However, given the risk of radiation induced pneumonitis, we would advocate that patients with limited physiological reserve should be carefully assessed and counselled prior to treatment. It is our experience that patients with an FEV1 as low as $0.4 \mathrm{~L}$ can be considered for SABR therapy provided the disease volume is low and adequate counselling of the patient is undertaken. Pulmonary fibrosis is typically considered to be a contraindication due to the potential of accelerating the inflammatory process leading to worsening of respiratory function ${ }^{28}$. There is some variation between oncologists regarding radiotherapy and in various subtypes of pulmonary fibrosis although there is consensus that this modality of treatment is contraindicated in Usual Interstitial Pneumonia (UIP).

The use of SABR to treat small $(<5 \mathrm{~cm})$ peripheral, node negative lesions is increasing. When planning for $S A B R$, tumours must be $>2 \mathrm{~cm}$ away from the bifurcation of the second order bronchus (the 'no fly' zone) and consideration must be given to OARs which include the spinal cord, heart, oesophagus and ipsilateral brachial plexus.

\section{Chemoradiotherapy}

Platinum based chemotherapy as part of chemoradiotherapy is the mainstay of treatment. Cisplatin or carboplatin are the two drugs most commonly used, in combination with one other cytotoxic agent such as etoposide, vinorelbine or paclitaxel. Chemotherapy can be given sequentially or concurrently with radiation. Cisplatin is the most studied agent but is nephrotoxic meaning dose reductions are advisable in patients with a glomerular filtration rates (GFR) $<60 \mathrm{ml} / \mathrm{min}$. At lower GFRs, substitution with carboplatin is required and platinum based chemotherapies are contraindicated in severe renal impairment. If considering cisplatin, a full assessment of renal function is required before, during and after treatment ${ }^{76}$. Adequate hydration including forced diuresis is required and patients must be able to tolerate a large intravenous fluid load. Other significant toxicities include neuropathy and high tone hearing loss which needs to be taken into consideration in those with these pre-existing co-morbidities.

A systematic review demonstrated the benefits of concurrent chemo-radiation, radiotherapy alone and sequential chemoradiotherapy, but noted increased toxicity including radiation oesophagitis meaning patient selection has to be an important consideration in deciding those who will most benefit ${ }^{77}$. 


\section{Optimisation of respiratory function}

\section{Smoking cessation}

Smoking cessation is always recommended in patients with lung malignancy and the majority of patients presenting with lung cancer will be either current smokers or ex-smokers. Current guidelines recommend that smoking cessation be advocated in patients being considered for surgical resection of lung cancer ${ }^{17,32,33}$. There is also increasing evidence that smoking can be detrimental to the efficacy of systemic chemotherapy agents used to treat lung cancer, by inducing enzymes which metabolise these medicines ${ }^{78}$, and can lead to increased rates of treatment-related pneumonitis in patients receiving definitive radiotherapy ${ }^{79}$. In addition, smoking cessation at the time of lung cancer diagnosis is likely to positively impact future respiratory health, reducing the likelihood of disease recurrence or development of further cancers ${ }^{80}$.

To date, there are no randomised controlled studies examining the impact of smoking cessation prior to surgery ${ }^{81}$. However, multiple studies have shown that patients with a smoking history (current or ex-smokers) have increased postoperative mortality and morbidity compared to neversmokers $^{82-86}$. One retrospective cohort study found that preoperative smoking cessation may reduce the risk of postoperative pulmonary complications, but for maximal benefit cessation should occur at least four weeks prior to surgery ${ }^{87}$. There are substantial limitations in many of the available studies into the timing of smoking cessation in lung cancer patients considered for lung resection, and current NICE guidelines (2011) advise that surgical treatment of lung cancer should not be postponed to allow patients to stop smoking ${ }^{17}$.

Although some methods of promoting smoking cessation have been found to have limited effectiveness (e.g. self-help information provision or being advised to stop smoking as part of a wider consultation) there is growing evidence that pharmacological interventions and more intensive smoking cessation therapy (such as formal cessation counselling) improve the likelihood of successful cessation ${ }^{85,88}$.

Over recent years there has been increasing interest in the role of new adjuncts such as electronic cigarettes (also known as e-cigarettes) in smoking cessation. The Royal College of Physicians have published a report exploring concerns around the safety of e-cigarettes and provided reassurance that long-term use of e-cigarettes is unlikely to exceed $5 \%$ of the harm from cigarette smoking ${ }^{89}$. The efficacy of e-cigarettes in smoking cessation also remains an area of contention. A randomised controlled trial published in 2013 suggested that e-cigarettes might improve abstinence from 
smoking compared to nicotine patches or placebo, but the results were not statistically significant as the study was underpowered; researchers had been anticipating higher overall abstinence rates ${ }^{90}$. A recent review and meta-analysis of the current use of e-cigarettes suggested that patients currently choosing to use e-cigarettes did not have increased rates of smoking cessation compared to other patients ${ }^{91}$. Certainly further randomised controlled studies evaluating the efficacy of e-cigarettes in smoking cessation are required.

\section{Medical Treatment of underlying lung disease}

Lung cancer often co-exists with COPD and/or pulmonary fibrosis and managing physicians should be alert to the possibility of improving lung function testing and performance status through medical therapy.

There is debate as to whether COPD is an independent risk factor for lung cancer or whether the relationship between the two diseases is simply due to a common pathogenic trigger ${ }^{92,93,94}$. Patients with COPD should have their condition optimised with inhaled therapy which will likely include combination inhalers (steroid and beta-2 agonist preparations) and anti-cholinergic therapies. Inhaled therapies have their actions on airway airflow obstruction and are generally ineffective for treating purely parenchymal disease. In some cases where a cancer is found within an area of severe emphysema, surgery can still be considered as a patient may benefit from a lung volume reduction effect ${ }^{94}$. Assessment for this should be undertaken with a surgeon experienced in lung volume reduction and cancer treatments. COPD does not usually preclude radiotherapy treatment.

As radiotherapy is typically contraindicated in patients with pulmonary fibrosis, sublobar resections such as wedge resections or segmentectomy procedures may be more appropriate as they will have a less deleterious effect on underlying lung reserve. Prior to surgery, gastro-oesophageal reflux disease should be treated and potentially reversible causes of inflammatory disease should be identified and treated.

\section{Pulmonary rehabilitation}

Pulmonary rehabilitation combines a course of education and exercises that aims to improve lung function and symptoms in patients with long-term respiratory conditions ${ }^{95}$. Postoperative pulmonary complications are the main cause of mortality in patients who have undergone surgical resection of lung cancer ${ }^{96}$. Pulmonary rehabilitation has been proven to be effective in candidates 
for lung-volume reduction surgery and for patients undergoing lung transplantation ${ }^{97,98,99}$. International guidelines have acknowledged that pulmonary rehabilitation may have a role in reducing complications for lung cancer resection patients.

A study performed by Gao et al demonstrated that patients receiving pulmonary rehabilitation prior to lobectomy had reduced postoperative complications and shorter hospital stays than those not receiving pulmonary rehabilitation ${ }^{100}$. Further studies have also suggested benefits in the postoperative functional status of patients receiving preoperative pulmonary rehabilitation, with increased VO2 max and a possible reduction in hospital length of stay following surgical resection ${ }^{101}$.

The exercise capacity of patients undergoing lung resection surgery is commonly reduced in the postoperative period, although many patients gradually regain function over the following year ${ }^{64}$. Several studies have shown improvement in dyspnoea (measured with the Borg scale), improved FEV1 and FVC, and 6 minute walk distance with postoperative pulmonary rehabilitation ${ }^{102,103}$. Although promising, these studies investigated low numbers of patients with differing treatment methodologies. A large prospective randomised trial found that although 6 minute walk distance was increased in patients undergoing postoperative pulmonary rehabilitation, the quality of life of the group was not significantly different ${ }^{104}$. They also found that commencing pulmonary rehabilitation soon after surgery led to increased reporting of postoperative pain, and in view of this the authors recommended delaying the start of pulmonary rehabilitation to 3-4 months post resection. Overall, the evidence suggests that there might be some benefit to preoperative and postoperative pulmonary rehabilitation in lung resection patients.

\section{Conclusion}

With an aging population and increasing disease complexity, the work-up, staging and physiological assessments of patients with lung cancer is becoming increasingly challenging. The patient being considered for treatment with curative intent is required to undergo multiple investigations to establish their suitability for treatments. Lung cancer management requires the integration of a well-functioning multidisciplinary team in order to achieve optimal results. Management planning should be considered in the context of not only treatment of the disease but also the short-and long-term sequelae of treatments, with reduced emphasis placed upon absolute physiological cutoffs and increased value placed upon discussion of risks with individual patients. 


\section{$\underline{\text { Figures }}$}

Figure 1- Overview of investigation pathway for patients under consideration for treatment with curative intent.

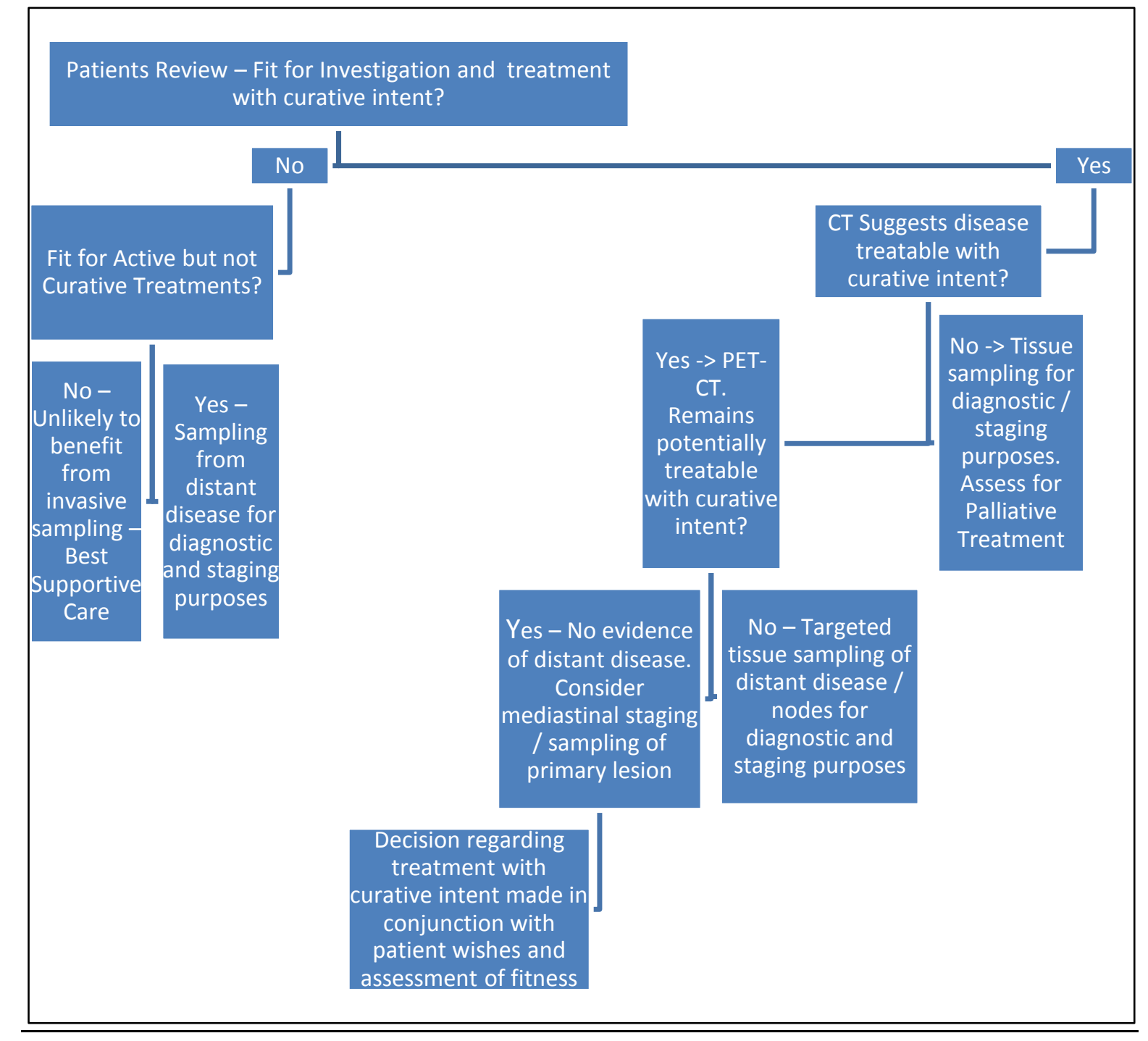


Figure 2- Tripartite risk assessment from the American College of Cardiology (ACC) and American Heart Association (AHA) - adapted from BTS 2010 guidelines $^{38,39}$.

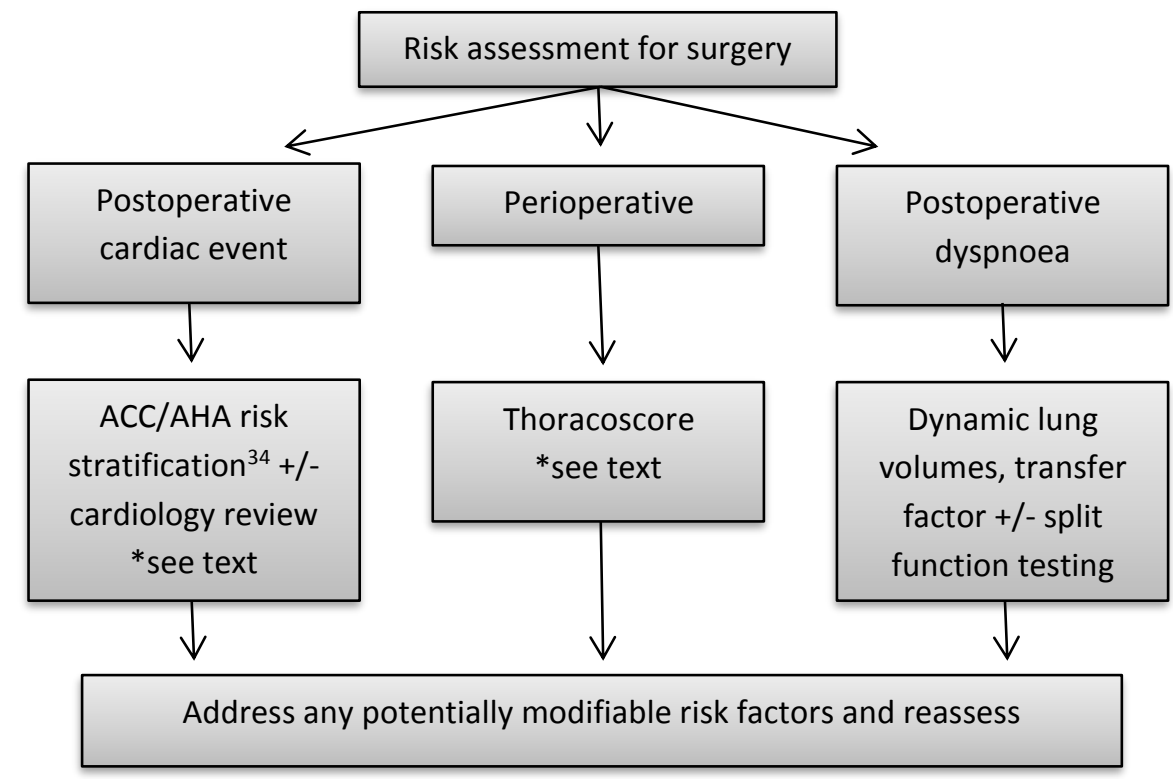

Does the patient accept the risk in each category +/- potential impact on lifestyle?

Exclude surgery from multimodality treatment multimodality management 
Figure 3- Adapted from Chest guidelines 2013, originally derived from ERS/ESTS clinical guidelines on fitness for lung resection in lung cancer patients ${ }^{32,33}$.

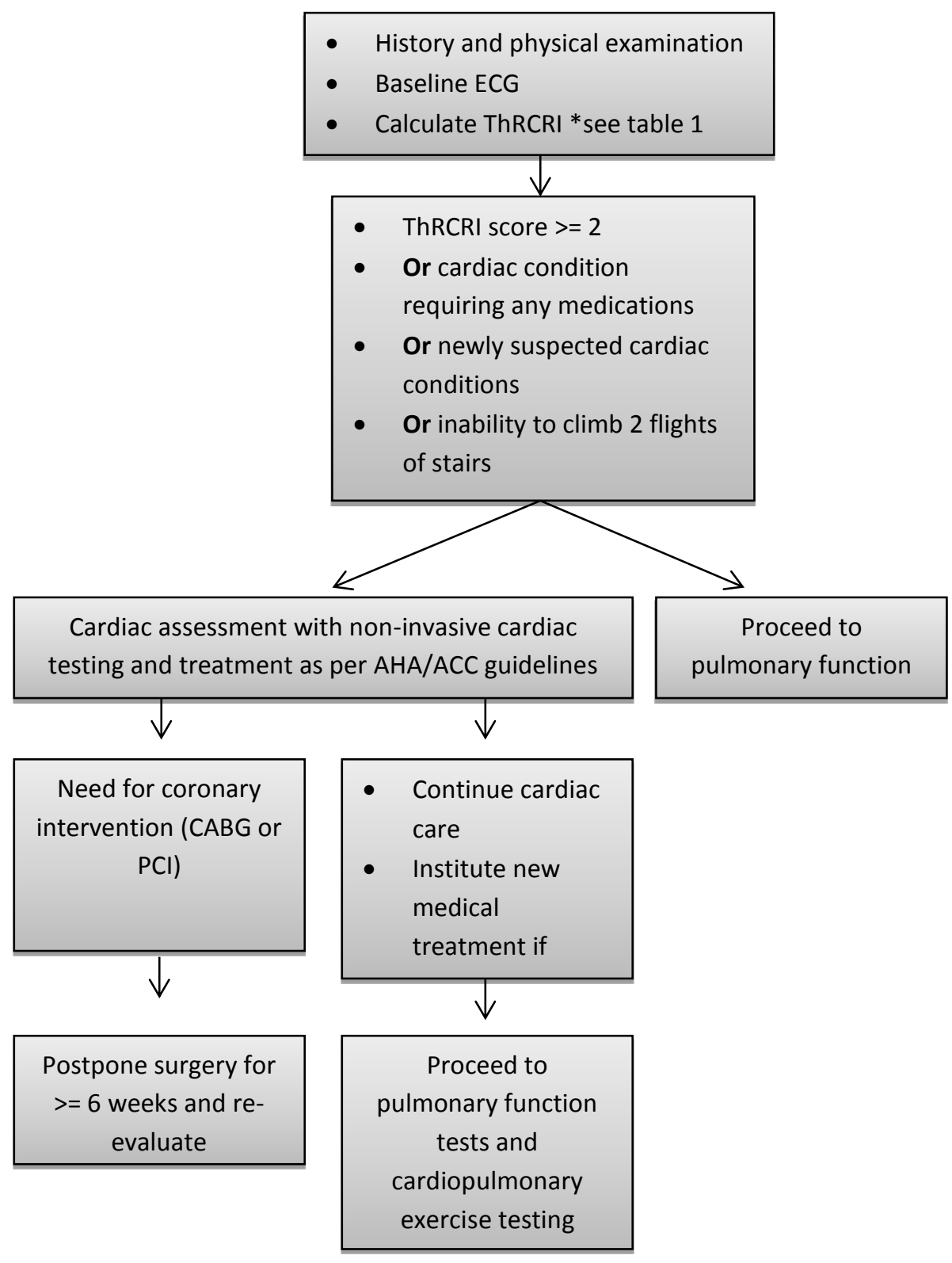


Figure 4- Lung Function physiologic evaluation resection algorithm- adapted from algorithm by Brunelli et al $2013^{32}$.

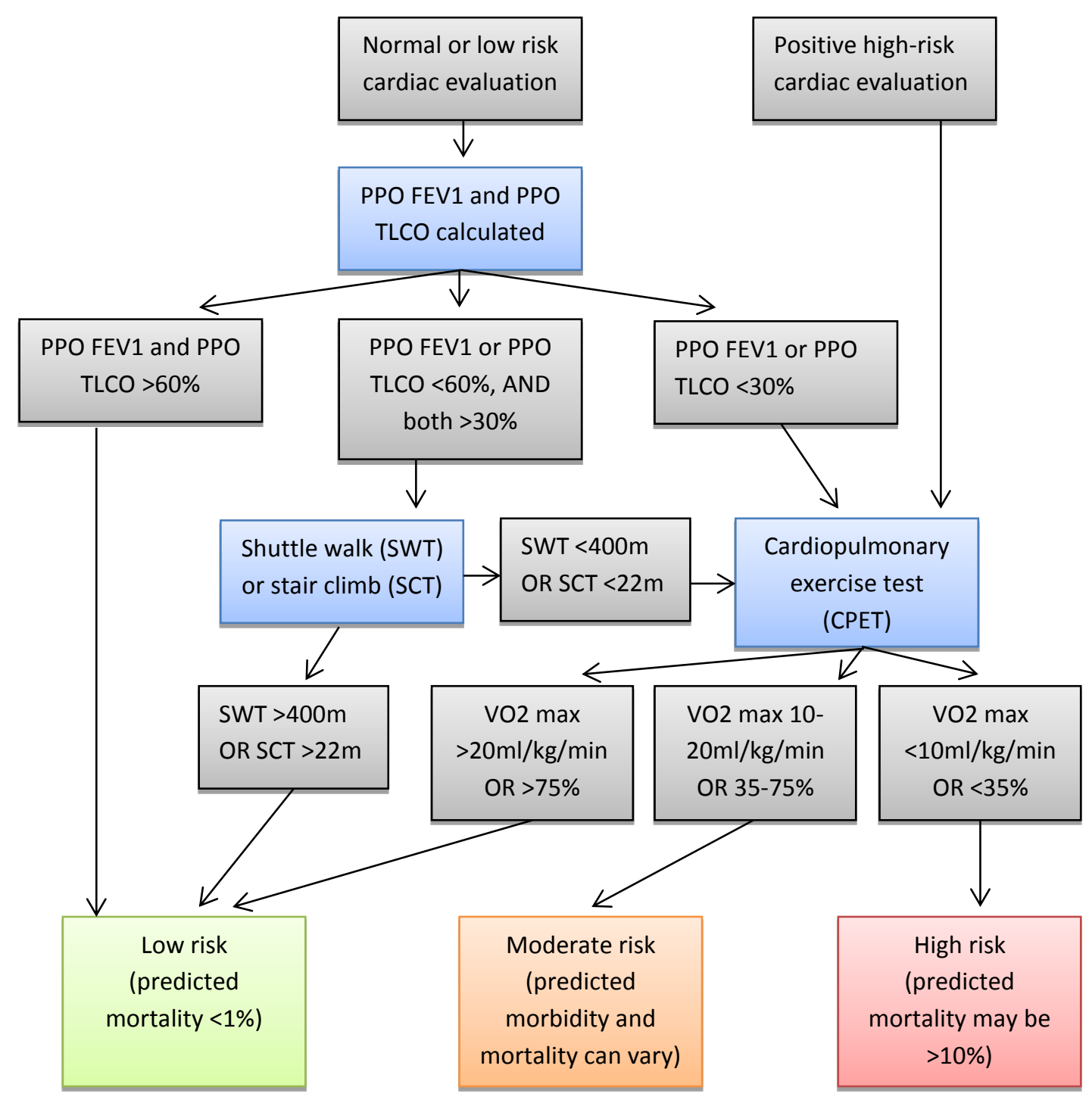




\section{$\underline{\text { Tables }}$}

Table 1- ECOG performance status, as published by the Eastern Cooperative Oncology Group $1982^{37}$

\begin{tabular}{|l|l|}
\hline $\mathbf{0}$ & ECOG performance status \\
\hline $\mathbf{1}$ & $\begin{array}{l}\text { Fully active, able to perform all pre-disease activities without } \\
\text { restriction }\end{array}$ \\
\hline $\mathbf{2}$ & $\begin{array}{l}\text { Restricted in physically strenuous activity but ambulatory and able to } \\
\text { carry out work of a light or sedentary nature }\end{array}$ \\
\hline $\mathbf{3}$ & $\begin{array}{l}\text { Ambulatory and capable of all self-care but unable to carry out work } \\
\text { activities; up and about more than 50\% of waking hours }\end{array}$ \\
\hline $\mathbf{4}$ & $\begin{array}{l}\text { Capable of only limited self-care; confined to bed or chair for more } \\
\text { than 50\% of waking hours }\end{array}$ \\
\hline
\end{tabular}

Table 2- ThRCRI scoring system. Table adapted from Brunelli et al $2010^{40}$.

\begin{tabular}{|lc|}
\hline Risk factor & Score \\
\hline \begin{tabular}{lc|} 
Creatinine $>=2 \mathrm{mg} / \mathrm{dl}$ & 1 \\
$(>177 \mu \mathrm{mol} / \mathrm{L})$, or on renal \\
replacement therapy
\end{tabular} \\
\hline Coronary artery disease & 1.5 \\
\hline Cerebrovascular disease & 1.5 \\
\hline Pneumonectomy & 1 \\
\hline
\end{tabular}

Table 3- Risk of major cardiac complications in patients undergoing major lung sections (lobectomy or pneumonectomy). Table adapted from Brunelli et al $2010^{40}$.

\section{Risk category ThRCRI score $\quad$ Major cardiac complications \\ (\% patients)}

\begin{tabular}{|lll|}
\hline A & 0 & 1.5 \\
\hline B & $1-1.5$ & 5.8 \\
\hline C & $2-2.5$ & 19 \\
\hline D & $>2.5$ & 23 \\
\hline
\end{tabular}




\section{$\underline{\text { References }}$}

1. Riaz $\mathrm{SP}$, Luchtenborg $\mathrm{M}$, Jack $\mathrm{RH}$, et al. Variation in surgical resection for lung cancer in relation to survival: Population-based study in England 2004-2006. Eur J Cancer 2012; 48: 54-60

2. Riaz SP, Linklater $\mathrm{KM}$, Page $\mathrm{R}$, et al. Recent trends in resection rates among non-small cell lung cancer patients in England. Thorax 2012; 67(9):811-4.

3. The Society for Cardiothoracic Surgery in Great Britain \& Ireland. Second National Thoracic Surgery Activity \& Outcomes Report 2011. http://www.scts.org/_userfiles/resources/634558869917493937_Thoracic_2011_FINAL.pdf

4. Liu HC, Huang WC, Wu CL, et al. Surgery for elderly lung cancer. Ann Thorac Cardiovasc Surg 2013;19(6):416-22.

5. Miura N, Kohono $\mathrm{M}$, Ito $\mathrm{K}$, et al. Lung cancer surgery in patients aged 80 years or older: an analysis of risk factors, morbidity, and mortality. Gen Thorac Cardiovasc Surg 2015 63:401-405

6. Falcoz PE, Puyraveau M, Thomas PA, et al; ESTS Database Committee and ESTS Minimally Invasive Interest Group. Video-assisted thoracoscopic surgery versus open lobectomy for primary non-small-cell lung cancer: a propensity-matched analysis of outcome from the European Society of Thoracic Surgeon database. Eur J Cardiothorac Surg 2015 26. pii: ezv154. [Epub ahead of print]

7. Higuchi $\mathrm{M}$, Yaginuma $\mathrm{H}$, Yonechi $\mathrm{A}$, et al. Long-term outcome after video-assisted thoracic surgery (VATS) lobectomy versus lobectomy via open thoracotomy for clinical stage IA Non-Small Cell Lung Cancer. Journal of Cardiothoracic Surgery 2014, 9:88

8. Soldà $F$, Lodge $M$, Ashley $S$, et al. Stereotactic radiotherapy (SABR) for the treatment of primary non-small cell lung cancer; systematic review and comparison with a surgical cohort. Radiother Oncol 2013 Oct;109(1):1-7

9. Senan S, Paul MA, Lagerwaard FJ. Treatment of early-stage lung cancer detected by screening: surgery or stereotactic ablative radiotherapy? Lancet Oncol 2013; 14: e270-74

10. Stapley S, Sharp D, Hamilton W. Negative chest X-rays in primary care patients with lung cancer. Br J Gen Pract. 2006 Aug 1; 56(529): 570-573.

11. Thirumaran M, Sundar R, Sutcliffe IM, et al. Is investigation of patients with haemoptysis and normal chest radiograph justified? Thorax. 2009; 64(10): 854-856.

12. Stapley S, Sharp D, Hamilton W. Negative chest X-rays in primary care patients with lung cancer. Br J Gen Pract 2006; 56 (529): 570 - 573. 
13. Silvestri GA, Gould MK, Margolis ML, et al; On behalf of the American College of Chest Physicians. Noninvasive staging of non-small cell lung cancer: ACCP evidenced-based clinical practice guidelines (2nd edition). Chest 2007;132(3 Suppl):178S-201S.

14. Gould MK, Kuschner WG, Rydzak CE, et al. Test performance of positron emission tomography and computed tomography for mediastinal staging in patients with non-small-cell lung cancer: a meta-analysis. Ann Intern Med 2003 Dec 2;139(11):879-92.

15. Darling GE, Maziak DE, Inculet RI, et al. Positron emission tomography-computed tomography compared with invasive mediastinal staging in non-small cell lung cancer: results of mediastinal staging in the early lung positron emission tomography trial. J Thorac Oncol 2011;6(8):1367-72.

16. Qu X, Huang $X$, Yan W, et al. A meta-analysis of ${ }^{18} \mathrm{FDG}$-PET-CT, ${ }^{18} \mathrm{FDG}$-PET, MRI and bone scintigraphy for diagnosis of bone metastases in patients with lung cancer. Eur J Radiol 2012;81(5):1007-15.

17. National Institute for Health and Clinical Excellence (2011). Lung Cancer Diagnosis and Management. NICE guideline (CG121).

18. Gerald Antoch MD. Non-Small Cell Lung Cancer: Dual-Modality PET/CT in Preoperative Staging. Radiology 2003; 229: 526-533

19. Al-Sarraf N, Aziz R, Gately K et al. Pattern and predictors of occult mediastinal lymph node involvement in non-small cell lung cancer patients with negative mediastinal uptake on positron emission tomography. Eur J Cardiothorac Surg 2008; 33(1):104-9.

20. Sagawa M, Sato M, Sakurada A, et al. A prospective trial of systematic nodal dissection for lung cancer by video-assisted thoracic surgery: can it be perfect? Ann Thorac Surg 2002; 73 (3): 900-4.

21. Licht PB1, Jørgensen OD, Ladegaard L, et al. A national study of nodal upstaging after thoracoscopic versus open lobectomy for clinical stage I lung cancer. Ann Thorac Surg 2013; 96(3): 943-9; discussion 949-50.

22. Boffa D, Kosinski A, Paul S, et al. Lymph node evaluation by open or video-assisted approaches in 11,500 anatomic lung cancer resections. Ann Thorac Surg 2012; 94: 347-353.

23. Annema JT, van Meerbeeck JP, Rintoul RC, et al. Mediastinoscopy vs endosonography for mediastinal nodal staging of lung cancer: a randomized trial. JAMA 2010; 304(20):2245-52.

24. Rintoul RC, Glover MJ, Hughes V et al. Audit, research and guideline update: Cost effectiveness of endosonography versus surgical staging in potentially resectable lung cancer: a health economics analysis of the ASTER trial from a European perspective. Thorax 2014; 69 (7): 679681. 
25. Defranchi SA, Edell ES, Daniels $\mathrm{CE}$, et al. Mediastinoscopy in patients with lung cancer and negative endobronchial ultrasound guided needle aspiration. Ann Thorac Surg 2010;90(6):17537

26. yasufuku K, Pierre A, Darling G, et al. A prospective controlled trial of endobronchial ultrasound guided transbronchial needle aspiration compared to mediastinoscopy for mediastinal lymph node staging of lung cancer. J Thorac Cardiovasc Surg 2011; 142: 1393-440

27. V Rusch. Mediastinoscopy: An obsolete procedure? J Thorac Cardiovasc Surg 2011; 142(6): 14001402.

28. Stereotactic Ablative Body Radiation Therapy (SABR): A Resource. Section II.2 "Patient Selection Criteria" UK Consortium. Version 4.0, January 2013. P. 12-30. http://actionradiotherapy.org/wpcontent/uploads/2014/03/UK-SABR-Consortium-Guidelines.pdf

29. Piccirillo JF, Vlahiotis A, Barrett LB, et al. The Changing Prevalence of Comorbidity Across the Age Spectrum. Crit Rev Oncol Hematol 2008; 67(2): 124-132

30. Massard G, Moog R, Wihlm JM, et al. Bronchogenic cancer in the elderly: operative risk and longterm prognosis. Thorac Cardiovasc Thorac Surg 1999; 44:44-45

31. Spyratos D, Zarogoulidis P, Porpodis K, et al. Preoperative evaluation for lung cancer resection. J Thorac Dis 2014; 6 (suppl 1): S162-S166.

32. Brunelli A, Kim A, Berger K, Addrizzo-Harris D. Physiologic Evaluation of the Patient with Lung Cancer Being Considered for Resectional Surgery: diagnosis and management of Lung Cancer $3^{\text {rd }}$ ed: American College of Chest Physicians Evidence-Based Clinical Practice Guidelines. Chest 2013: 143 (5)(suppl): e166S-e190S.

33. Brunelli A, Charloux A, Bollinger C, et al. ERS/ESTS clinical guidelines on fitness for radical therapy in lung cancer patients (surgery and chemo-radiotherapy). Eur Respir J 2009; 34(1):1741.

34. Pallis A, Gridelli C, van Meerbeeck J et al. EORTC Elderly Task Force and Lung Cancer Group and International Society for Geriatric Oncology (SIOG) experts' opinion for the treatment of nonsmall cell lung cancer in an elderly population. Ann Oncol 2010;21(4):692-706.

35. Buccheri G, Ferrigno D, Tamburini M. Karnofsky and ECOG performance status scoring in lung cancer: A prospective, longitudinal study of 536 patients from a single institution. Eur J Cancer 1996; 32 (7): 1135-1141.

36. Hutchinson T, Boyd N, Feinstein A. Scientific problems in clinical scales, as demonstrated in the Karnofsky index of performance status. J Chronic Dis 1979; 32 (9-10): 661-666.

37. Oken $\mathrm{M}$, Creech R, Tormey D, et al. Toxicity and response criteria of the Eastern Cooperative Oncology Group. Am J Clin Oncol 1982; 5 (6): 649-655. 
38. Thorax, Guidelines on the Radical Management of Patients with Lung Cancer, Oct 2010. Vol 65 Supp III.

39. Fleisher LA, Beckman JA, Brown KA, et al. ACC/AHA 2007 Guidelines on perioperative cardiovascular evaluation and care for noncardiac surgery: A report of the American College of Cardiology/American Heart Association Task Force on Practice Guidelines, developed in collaboration with the American Society of Echocardiography, American Society of Nuclear Cardiology, Heart Rhythm Society, Society of Cardiovascular Anesthesiologists, Society for Cardiovascular Angiography and Interventions, Society for Vascular Medicine and Biology, and Society for Vascular Surgery. J Am Coll Cardiol 2007; 50:e159-241.

40. Brunelli A, Varela G, Salati M, et al. Recalibration of the revised cardiac risk index for predicting the risk of major cardiac complications after lung resection. Ann Thorac Surg 2010;90(1):199203.

41. Jeger $R$, Probst $C$, Arsenic $R$, et al. Long-term prognostic value of the pre-operative 12-lead electrocardiogram before major non-cardiac surgery in coronary artery disease. Am Heart J 2006; 151: 508-513

42. Lee $\mathrm{T}$, Marcantonio E, Mangione $\mathrm{C}$, et al. Derivation and prospective validation of a simple index for prediction of cardiac risk of major non-cardiac surgery. Circulation 1999; 100: 1043-1049.

43. Brunelli A, Cassivi S, Fibla J, et al. External validation of the recalibrated thoracic revised cardiac risk index for predicting the risk of major cardiac complications after lung resection. Ann Thorac Surg 2011; 92: 445-448.

44. Ferguson M, Celauro A, Vigeswaran W. Validation of a modified scoring system for cardiovascular risk associated with major lung resection. Eur J Cardiothorac Surg 2012; 41: 598602.

45. Bangalore S, Wetterslev J, Pranesh S, et al. Perioperative beta blockers in patients having noncardiac surgery: a meta-analysis. Lancet 2008;372:1962e76.

46. Kristensen S, Knuuti J, Saraste A, et al. 2014 ESC/ESA guidelines on non-cardiac surgery: cardiovascular assessment and management. Eur Heart J 2014; 35 (35): 2383-2431.

47. Bourni S, Shun-Shin M, Cole G, et al. Meta-analysis of secure randomised controlled trials of Bblockade to prevent perioperative death in non-cardiac surgery. Heart 2014; 100: 456- 464.

48. Montalescot G, Sechtem U, Achenbach S, et al. 2013 ESC guidelines on the management of stable coronary artery disease: The task force on the management of stable coronary artery disease of the European Society of Cardiology. Eur Heart J 2013; 34: 2949-3003.

49. Etchells E, Meade M, Tomlinson G, Cook D. Semi-quantitative dipyridamole myocardial stress perfusion imaging for cardiac risk assessment before non-cardiac vascular surgery: A meta- 
analysis. J Vasc Surg 2002;36:534-540.

50. Eagle KA, Rihal CS, Mickel MC, et al. Cardiac risk of non-cardiac surgery: influence of coronary disease and type of surgery in 3368 operations. Circulation 1997;96:1882e7.

51. NHS information centre. National lung cancer audit 2012, report for the audit period 2011. 2012.

52. Powell H, Tata L, Baldwin D, et al. Early mortality after surgical resection for lung cancer: an analysis of the English National Lung Cancer audit. Thorax 2013; 68: 826- 834.

53. Falcoz P.E. et al. The Thoracic Surgery Scoring System (Thoracoscore): Risk model for in-hospital death in 15,183 patients requiring thoracic surgery. J Thorac Cardiovasc Surg 2007; 133: 325-32

54. Chamogeorgakis T, Connery C, Bhora F, et al. Thoracoscore predicts midterm mortality in patients undergoing thoracic surgery. J Thorac Cardiovasc Surg 2007; 134: 883-887.

55. Qadri S, Jarvis M, Ariyaratnam P, et al. Could Thoracoscore predict postoperative mortality in patients undergoing pneumonectomy? Eur J Cardiothorac Surg 2014; 45 (5): 864-869.

56. Sharkey A, Ariyaratnam P, Anikin V, et al. Thoracoscore and European Society Objective Score fail to predict mortality in the UK. World J Oncol 2015; 6 (1): 270-275.

57. Qadri S, Chaudhry M, Cale A, et al. Short- and long-term outcomes of pneumonectomy in a tertiary center. Asian Cardiovasc Thorac Ann 2016; 24 (3): 250-256.

58. Bollinger $\mathrm{C}$, Jordan $\mathrm{P}$, Soler $\mathrm{M}$, et al. Pulmonary function and exercise capacity after lung resection. Eur Respir J 1996; 9: 415-421.

59. Ferguson $\mathrm{M}$, Vigneswaran $\mathrm{W}$. Diffusing capacity predicts mortality after lung resection in patients without obstructive lung disease. Ann Thorac Surg 2008; 85: 1158- 1164.

60. Gould G, Pearce A. Assessment of suitability for lung resection. Continuing education in Anaesthesia, Critical Care and Pain 2006; 6 (3): 97-100.

61. Win T, Jackson A, Sharples L, et al. Cardiopulmonary exercise tests and lung cancer surgical outcome. Chest 2005; 127:1159-1165.

62. Brunelli A, Salati M. Preoperative evaluation of lung cancer: predicting the impact of surgery on physiology and quality of life. Curr Opin Pulm Med 2008; 14 (4): 275-281.

63. Brunelli A, Refai M, Salati M, et al. Predicted versus observed FEV1 and DLCO after major lung resection: a prospective evaluation at different postoperative periods. Ann Thorac Surg 2007; 83: 1134-1139.

64. Brunelli A, Xiume F, Refai M, et al. Evaluation of expiratory volume, diffusion capacity and exercise tolerance following major lung resection: a prospective follow-up analysis. Chest 2007; 131: 141-147. 
65. Kushibe K, Takahama M, Tojo T, et al. Assessment of pulmonary function after lobectomy for lung cancer- upper lobectomy might have the same effect as lung volume reduction surgery. Eur J Cardiothorac Surg 2006; 29 (6): 886-890.

66. Edwards J, Duthrie D, Waller D. Lobar volume reduction surgery: a method of increasing the lung cancer resection rate in patients with emphysema. Thorax 2001; 56 (10): 791-795.

67. Varela G, Brunelli A, Rocco G, et al. Predicted versus observed FEV1 in the immediate postoperative period after pulmonary lobectomy. Eur J Cardiothorac Surg 2006; 30(4): 644-8.

68. Varela G, Brunelli A, Rocco G, et al. Measured FEV1 in the first postoperative day, and not ppoFEV1, is the best predictor of cardio-respiratory morbidity after lung resection. Eur J Cardiothorac Surg 2007; 31(3): 518-21.

69. Holden D, Rice T, Stelmach K, et al. Exercise testing, 6-minute walk, and stair climb in the evaluation of patients at high risk for pulmonary resection. Chest 1992; 102: 1774-1779.

70. Pierce R, Copland J, Sharpe K, et al. Preoperative risk evaluation for lung cancer resection: predicted postoperative product as a predictor of surgical mortality. Am J Respir Crit Care Med 1994; 150: 947-955.

71. Singh S, Morgan M, Hardman A, et al. Comparison of oxygen uptake during a conventional treadmill test and the shuttle walking test in chronic airflow obstruction. Eur Respir J 1994; 7: 2016-2020.

72. Win T, Jackson A, Groves A, et al. Relationship of shuttle walk test and lung cancer surgical outcome. Eur J Cardiothorac Surg 2004; 26: 1216-1219.

73. Colice G, Shafazand S, Griffin J, et al. Physiologic evaluation of the patient with lung cancer being considered for resectional surgery: ACCP evidence-based clinical practice guidelines ( $2^{\text {nd }}$ Edition). Chest 2007; 132: Suppl. 3, 161S-177S.

74. Corris $\mathrm{P}$, Ellis $\mathrm{D}$, Hawkins $\mathrm{T}$, et al. Use of radionucleotide scanning in the preoperative estimation of pulmonary function after pneumonectomy. Thorax 1987; 42: 285-291.

75. Win T, Tasker A, Groves A, et al. Ventilation-perfusion scintigraphy to predict postoperative pulmonary function in lung cancer patients undergoing pneumonectomy. AJR Am J Roentgenol 2006; 187: 1260-1265.

76. Nortier, J, Sculier, J-P. Thoracic malignancies, cisplatin and renal function. Eur Respir J 2011; 37 (4): $760-761$

77. O'Rourke N, Figuls $\mathrm{M}$, Bernardo $\mathrm{N}$ et al. Concurrent chemoradiotherapy in non-small cell lung cancer. Cochrane Database Syst Rev 2010; 6: CD002140.

78. O'Malley M, King A, Conte M, et al. Effects of cigarette smoking on metabolism and effectiveness of systemic therapy for lung cancer. J Thorac Oncol 2014; 9 (7): 917-926. 
79. Jin H, Tucker S, Liu H, et al. Dose-volume thresholds and smoking status for the risk of treatmentrelated pneumonitis in operable non-small cell lung cancer treated with definitive radiotherapy. Radiother Oncol 2009; 91 (3): 427-432.

80. Sardari N, Weyler J, Colpaert C, et al. Prognostic value of smoking status in operated non-small cell lung cancer. Lung Cancer 2005; 47: 351-359.

81. Schmidt-Hansen M, Page R, Hasler E. The Effect of Preoperative Smoking Cessation or Preoperative Pulmonary Rehabiliation on Outcomes After Lung Cancer Surgery: A Systematic Review. Clin Lung Cancer 2013; 14 (2): 96-102.

82. Barrera R, Shi W, Anwar D, et al. Smoking and time of cessation: impact on pulmonary complications after thoracotomy. Chest 2005; 127: 1977-1983.

83. Groth S, Whitson B, Kuskowski M, et al. Impact of preoperative smoking status on postoperative complication rates and pulmonary function test results 1-year following pulmonary resection for non-small cell lung cancer. Lung Cancer 2009; 64: 352-357.

84. Mason D, Subramanian S, Nowicki E, et al. Impact of smoking cessation before resection of lung cancer: a society of thoracic surgeons general thoracic surgery database study. Ann Thorac Surg 2009; 88: 362-370.

85. Leone F, Evers-Casey S, Toll B et al. Treatment of tobacco use in lung cancer: diagnosis and management of lung cancer, $3^{\text {rd }}$ ed: American College of Chest Physicians evidence-based clinical practice guidelines. Chest 2013; 143 (5)(suppl): e437S-e454S.

86. Lugg S, Tikka T, Kerr A, et al. Smoking at the time of curative-intent lung cancer surgery dramatically influences peri-operative complications. Eur Respir J 2015; 46 (suppl 59): PA2518.

87. Nakagawa $\mathrm{M}$, Tanaka $\mathrm{H}$, Tsukuma $\mathrm{H}$, et al. Relationship between the duration of preoperative smoke-free period and the incidence of postoperative pulmonary complications after pulmonary surgery. Chest 2001; 120: 705-710.

88. Thomsen T, Villebro N, Moller A. Interventions for preoperative smoking cessation. Cochrane Database Syst Rev 2014; (3): CD002294.

89. Tobacco Advisory Group of the Royal College of Physicians. Nicotine without smoke- tobacco harm reduction. Royal College of Physicians, 2016.

90. Bullen $\mathrm{C}$, Howe $\mathrm{C}$, Laugesen $\mathrm{M}$, et al. Electronic cigarettes for smoking cessation: a randomised controlled trial. Lancet 2013; 382 (9905): 1629-1637.

91. Kalkhoran S, Glantz S. E-cigarettes and smoking cessation in real-world and clinical settings: a systematic review and meta-analysis. Lancet Respir Med 2016; 4 (2): 116-128.

92. Takiguchi, Y, Sekine, I, Iwasawa, S, et al. Chronic obstructive pulmonary disease as a risk factor for lung cancer. World J Clin Onco 2014; 5(4): 660-666 
93. Powell HA, Iyen-Omofoman B, Baldwin DR, et al. Chronic obstructive pulmonary disease and risk of lung cancer: the importance of smoking and timing of diagnosis. J Thorac Oncol.2013; 8(1):611.

94. Raviv S, Hawkins KA, DeCamp Jr, et al. Lung Cancer in Chronic Obstructive Pulmonary Disease. Am J Respir Crit Care Med 2011; 183 (9): 1138-1146

95. British Lung Foundation (2014). Pulmonary Rehabilitation. [ONLINE] Available at: https://www.blf.org.uk/support-for-you/exercise/pulmonary-rehabilitation. [Accessed 12 March 16].

96. Putila J, Guo NL. Combining COPD with clinical, pathological and demographic information refines prognosis and treatment response prediction of non-small cell lung cancer. PLOS ONE 2014; 9 (6): e100994.

97. Bartels MN, Kim H, Whiteson JH, et al. Pulmonary rehabilitation in patients undergoing lungvolume reduction surgery. Arch Phys Med Rehabil 2006; 87 (Suppl. 1): S84-S88.

98. Ries AL, Make BJ, Lee SM, et al. The effects of pulmonary rehabilitation in the national emphysema treatment trial. Chest 2005; 128 (6): 3799-3809.

99. Palmer SM, Tapson VF. Pulmonary rehabilitation in the surgical patient. Lung transplantation and lung volume reduction surgery. Respir Care Clin N Am 1998; 4 (1): 71-83.

100. Gao K, Yu P, Su J, et al. Cardiopulmonary exercise testing screening and pre-operative pulmonary rehabilitation reduce postoperative complications and improve fast-track recovery after lung cancer surgery. Thorac Cancer 2015; 6 (4): 443-449.

101. Rivas-Perez $\mathrm{H}$, Nana-Sinkam P. Integrating pulmonary rehabilitation into the multidisciplinary management of lung cancer: A review. Respir Med 2015; 109: 437-442.

102. Spruit $\mathrm{M}$, Janssen $\mathrm{P}$, Willemsen $\mathrm{S}$, et al. Exercise capacity before and after an 8-week multidisciplinary inpatient rehabilitation program in lung cancer patients: a pilot study. Lung cancer 2006; 52 (2): 257-260.

103. Cesario A, Ferri L, Galetta D, et al. Post-operative respiratory rehabilitation after lung resection for non-small cell lung cancer. Lung cancer 2007; 57 (2): 175-180.

104. Stigt J, Uil S, Riesen S, et al. A randomised controlled trial of post thoracotomy pulmonary rehabilitation in patients with resectable lung cancer. J Thorac Oncol 2013; 8 (2): 214-221. 